\title{
A HOSPITALIDADE NOS HOTÉIS DA CIDADE DE ITAJAÍ (SC) NO SÉCULO XIX
}

HOSPITALITY IN THE HOTELS OF THE CITY OF ITAJAÍ (SC) IN THE 19TH CENTURY

\section{LA HOSPITALIDAD EN LOS HOTELES DE LA CIUDAD DE ITAJAÍ (SC) EN EL SIGLO XIX}

\begin{abstract}
Diva de Mello Rossini
Professora no Programa de Pós-graduação em Turismo e Hotelaria e Graduação de Arquitetura e Urbanismo e Design de Interiores da Universidade do Vale do Itajaí (UNIVALI) Doutora em Administração e Turismo pela Universidade do Vale do Itajaí (UNIVALI). divarossini@univali.br
\end{abstract}

Carlos Alberto Tomelin Vice-Reitor de Planejamento e Desenvolvimento Institucional e Tesoureiro da Universidade do Vale do Itajaí (UNIVALI) Doutor em Administração e Turismo pela Universidade do Vale do Itajaí (UNIVALI) tomelin@univali.br

Amélia Keller Solano
Graduanda em Arquitetura e Urbanismo na Universidade do
Vale do Itajaí (UNIVALI)
Graduada em Design Gráfico pela Universidade Regional do Noroeste do Estado do Rio
Grande do Sul (UNIJUI)
ameliakellerdesign@gmail.com
Data de Submissão: $07 / 07 / 2017$
Data de Aceitação: $11 / 11 / 2017$

RESUMO: Este artigo teve como objetivo identificar nos registros dos acervos históricos de Itajaí (SC) os edifícios hoteleiros que atendiam esta cidade no século XIX, assim como estudar o material encontrado com intuito de identificar a aplicação de conceitos de hospitalidade. O método qualitativo norteou as incursões exploratoriás em documentos, bibliográfias, bem como nas análises. Os resultados alcançados demonstram que poucos são os registros sobre os hotéis. O material encontrado sobre o Hotel Brazil permitiu analisar questões referentes à hospitalidade, inclusive em seu projeto arquitetônico, elementos detentores de alto potencial de atratividade turística. Os demais hotéis foram identificados por meio de manchetes de jornais, em que alguns conceitos de hospitalidade foram abordados, assim como informações sobre posturas higiênico-sanitárias.

PALAVRAS-CHAVE: Edifícios Hoteleiros. Hospitalidade. Projeto Arquitetônico.

ABSTRACT: This article aimed to identify, in the records of the historical collections of Itajai (SC), the hotel buildings that served this city in the nineteenth century. It also studies the material found, in order to identify the application of the concepts of hospitality. The qualitative method guided the exploratory incursions into documents and bibliographies, as well as the analyses. The results show that there are few records on hotels. The material found on the Hotel Brazil allowed us to analyze questions related to hospitality, including its architectural design, elements with high potential for tourist attractiveness. The other hotels were identified through newspaper headlines in which some concepts of hospitality were addressed, as well as information about attitudes to sanitation and hygiene. 
KEYWORDS: Hotel Buildings. Hospitality. Architectural design.

RESUMEN: Este artículo tuvo como objetivo identificar en los registros de los acervos históricos de Itajaí (SC) los edificios hoteleros que atendían esta ciudad en el siglo XIX, así como estudiar el material encontrado con el propósito de identificar la aplicación de conceptos de hospitalidad. El método cualitativo orientó las incursiones exploratorias en documentos, bibliografías y en los análisis. Los resultados alcanzados demuestran que son pocos los registros sobre los hoteles. El material encontrado sobre el Hotel Brazil permitió analizar cuestiones referentes a la hospitalidad, inclusive en su proyecto arquitectónico, elementos que poseen alto potencial de atractivo turístico. Los demás hoteles fueron identificados por medio de titulares de periódicos en los que se abordaban algunos conceptos de hospitalidad, así como informaciones sobre posturas higiénico sanitarias.

PALABRAS CLAVE: Edificios Hoteleros. Hospitalidad. Proyecto Arquitectónico.

\section{INTRODUÇÃO}

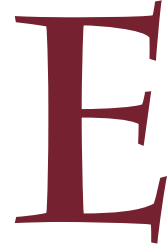

ste estudo teve como objetivo identificar os hotéis que serviam a cidade de Itajaí (SC) no século XIX, e nos registros históricos buscar indícios da aplicação de alguns conceitos que norteavam a hospitalidade da época.

As atividades econômico-financeiras de Itajaí no século XIX eram decorrentes de transações portuárias, as quais impulsionaram o desenvolvimento de equipamentos de apoio ao viajante que se deslocava até esta cidade, principalmente dos hotéis, que à época, além da hospedagem, ofereciam alimentação e locais para a realização de negócios. Convém ressaltar que o Porto de Itajaí era e continua a ser o principal ponto de importação e exportação de produtos de Santa Catarina, sendo que, à época, o principal produto exportado era a madeira extraída de todo o Vale do Itajaí (D’ávila, 1982).

Os meios de hospedagem para bem receber associam as relações do espaço físico com as sociais, as quais podem contribuir aproximando ou afastando as pessoas. Dentre os elementos que demonstram hospitalidade está o espaço físico, ou seja, a arquitetura dos hotéis é um elemento que se caracteriza como um diferencial que pode ser reconhecido pelos estudos turísticos, tanto em termos de exame crítico de autenticidade como em explorações reflexivas de dinâmicas sociais por meio das quais a produção cultural se realiza, lugares onde o turismo acontece como um resultado da 
identidade, da memória e dos significados de uma civilização (Lew, Hall \& Williams, 2004).

E ao refletir sobre as relações sociais, compreende-se que estas não podem ser desvinculadas dos locais onde aconteceram, nem da influência que este ambiente exerceu sobre o seu usuário (Raffestin, 1993).

Ao optar por pesquisar sobre hospitalidade, compreende-se que estudiosos a tratam como algo pleno de ambiguidades, devido à sua relação com a satisfação das pessoas e também por estar ligada à qualidade do relacionamento instituída entre o anfitrião e o hóspede, fato que tem instigado discussões junto à comunidade científica, pois vem gerando muitas controvérsias (Camargo, 2008).

Sendo assim, procurou-se conhecer, sem a intenção de esgotar o repertório existente, os conceitos de hospitalidade que podem ter norteado os projetos arquitetônicos dos hotéis de Itajaí do século XIX. Para tanto, foram realizados estudos sobre o surgimento do hotel em várias partes do mundo e no Brasil, alguns conceitos de hotel, as relações do hotel com a hospitalidade; quando e como o território que hoje é Itajaí foi ocupado e quais foram os principais fatos que nortearam o seu processo de transformação até o século XIX. Incursões exploratórias foram realizadas em documentos de acervos históricos, com o intuito de identificar quais foram os hotéis que serviram a sociedade desta época, qual a sua história, como eram os projetos arquitetônicos e quais eram as suas relações com a sociedade.

Com o encaminhamento das análises, elaboradas a partir dos preceitos da investigação qualitativa, foi possível verificar que a hipótese formulada de que os edifícios de hospedagem da cidade de Itajaí (SC), construídos no século XIX, possuem registros que traduzem fisicamente os conceitos de hospitalidade da época, foi parcialmente confirmada, pois poucos foram os documentos que demonstram a morfologia do edifício. Ou seja, o único projeto arquitetônico encontrado refere-se ao Hotel Brazil. A existência dos demais hotéis foi confirmada por meio de manchetes de jornais, cujas relações com os conceitos de hospitalidade reportam-se à venda da hospedagem e também atuam como um veiculador da aplicação das posturas higiênicosanitárias, tão importantes para a época. Vale ressaltar que apontamentos 
sobre outros tipos de edifícios de hospedagem não foram identificados, embora se acredite que devam existir.

Também foi possível constatar que apenas o edifício que abriga o antigo Hotel Brazil, hoje Hotel do Rota Mar, ainda permanece na malha urbana da cidade; todos os demais desapareceram, levando consigo parte da história desta sociedade. De alguns destes hotéis, nem sua localização foi encontrada, pois os documentos dos acervos estudados não possuíam este registro.

Vale ressaltar que este tipo de resultado não deve servir para desencorajar outras investigações desta natureza, muito pelo contrário, deve servir como um estímulo para que muitas outras sejam desenvolvidas, pois os resultados obtidos ainda deixam muitas dúvidas, principalmente sobre questões relativas à hospitalidade nos projetos arquitetônicos. Entretanto, outros dados importantes foram levantados, como a existência de outros hotéis do século XIX, os quais constam em pequenos recortes de jornal, importantes equipamentos que fizeram parte da história desta sociedade, informações que constam neste artigo e que contribuirão para a perpetuação e a divulgação da existência destes bens patrimoniais.

Compreende-se que as informações que constam nos acervos sejam precárias em detalhes, principalmente naqueles que versam sobre a existência destes importantes edifícios, mas se acredita que este fato se deva às dificuldades da época em registrar e armazenar os documentos, pois estes documentos são registros em papel, um material perecível, que pode ser perdido de diversas formas, diferente da demolição de um edifício, que implica uma série de equipamentos e custos. O que leva a pensar e perguntar sobre o fato de que em outros contextos citadinos, no mundo, ao se caminhar pelas ruas, encontramse edifícios que retratam a evolução histórica das cidades e no Brasil são raras estas experiências.

Espera-se estar provocando o surgimento de muitas outras perguntas, perguntas que mobilizem a sociedade a pensar sobre o patrimônio histórico material e imaterial e instigue a elaboração de políticas públicas que atuem em prol da preservação, da manutenção e da conservação do patrimônio edificado brasileiro, objeto que perpetua parte de nossa história, da memória 
e da identidade de nossa sociedade. Uma sociedade que tem passado por tantas mudanças, cujas peculiaridades certamente também são de interesse de outras comunidades, as quais poderão se deslocar até Itajaí para conhecê-las. E assim, também impulsionar o desenvolvimento da educação patrimonial, da preservação dos bens culturais e, por consequência, do turismo em Itajaí, em Santa Catarina e no Brasil.

\section{O HOTEL}

O processo de deslocamento humano para outras localidades e o contato com outras sociedades e culturas datam dos primórdios da civilização, embora a motivação para este ato nem sempre tem sido a mesma

A Europa, os séculos XVIII e XIX foram marcados por grandes mudanças econômicas, sociais e culturais promovidas pelo processo de industrialização. Aliado a este evento, ocorrem também alterações nas necessidades dos turistas, que devido à evolução dos meios de transporte, passam a desejar destinos antes inacessíveis. Dentre estes desejos surgem outros, como a necessidade de confortos junto aos meios de hospedagem. Sendo assim, autores como John Urry (1996) e Lima (2013) afirmam que o turismo, como atividade econômica e social, é própria do mundo moderno, o qual foi inaugurado pelo processo de industrialização e internacionalização do capital promovido pelas revoluções burguesas.

E que a ideia de hotel está ligada aos castelos e aos palácios que hospedavam as famílias reais e suas escoltas, cortes, sábios, músicos, artistas. Locais de elevados requintes da hospitalidade (Castelli, 1982). Mas foi no final do século XIX que surgiram os movimentos em prol da organização dos hotéis, época em que foi fundado o Conselho Internacional de hoteleiros. A Inglaterra foi a precursora do turismo e da hotelaria e perdeu a sua liderança para os Estados Unidos nos idos dos anos 1950. Mas foi no final do século XX, na segunda metade da década de 1990, com o aumento da velocidade da globalização da economia e a circulação dos capitais internacionais, que os investimentos nos meios de hospedagem aumentaram em todo o mundo (Campos \& Gonçalves, 1998). 
No Brasil, os serviços de hospedagem iniciam no período de colonização, com o intuito de acomodar os portugueses, contudo o modelo inicialmente adotado foi o europeu e, posteriormente, o norte-americano (Campos \& Gonçalves, 1998).

Uma das primeiras hospedarias em São Paulo foi a Casa Anchieta, que no século XVI abrigava os religiosos da Companhia de Jesus (Campos \& Gonçalves, 1998).

Nesta época os viajantes hospedavam-se nos casarões de engenho e fazendas, também era comum recebê-los como hóspedes em casa. Já os jesuítas e outras ordens religiosas recebiam pessoas nos conventos e nos mosteiros. Decorrente deste fato, no século XVIII, o mosteiro de São Bento foi construído no Rio de Janeiro, especificamente para abrigar visitantes ilustres. Com a chegada da corte portuguesa, século XIX, aumentou o fluxo de pessoas e a necessidade de que as hospedarias e tavernas adotassem a denominação de hotel (Andrade, Brito\& Jorge, 2000).

Antes do desenvolvimento dos hotéis, século XIX, as primeiras hospedarias eram estabelecimentos que ofereciam algum serviço diferenciado. Esta atividade era sempre desenvolvida em conjunto com outros ofícios, como barbearias, sapateiros, alfaiates. Todos eram considerados vendedores de alimentos e hospedagem (Duarte, 1996).

Em 1858, no Rio de Janeiro, havia 195 estabelecimentos, entre estalagens, hospedarias e hotéis, sendo que destes 78 pertenciam a brasileiros (Trigo, 2000).

NoSegundo Império, as crescentes pressões para a abolição da escravatura e independência influenciaram sobremaneira a atividade hoteleira. Assim como a substituição da mão de obra escrava pela dos imigrantes, na agricultura, fato que incentivou a diversificação das atividades comerciais e industriais (Duarte, 1996).

Neste mesmo século, em São Paulo, surgiram pequenos hotéis influenciados pelos hábitos europeus, com boa e farta comida e vinho generoso. Estes empreendimentos foram impulsionados com a ligação férrea de Santos a capital. Este movimento promoveu uma ascensão no setor hoteleiro, 
estimulando o crescimento dos edifícios, como foi o caso do Hotel Terminus, com mais de 200 quartos; e o Hotel Esplanada, com 250 apartamentos, hall de entrada revestido em mármore e três salões luxuosos, com serviço de restaurante e salões para chá. Estes foram os grandes marcos da hotelaria paulista (Andrade; Brito; Jorge, 2000).

\section{CONCEITOS DE HOTEL}

Beni (2003), um grande estudioso, define hotel como uma empresa de prestação de serviços, que se diferencia de outros estabelecimentos industriais e comerciais, pois o seu produto não vai até o consumidor, mas os clientes dirigem-se até ele para iniciar o seu esquema operacional. Também enfatiza o fato de o hotel se tratar de um empreendimento comercial de características únicas, cuja função básica é alojar. Outra característica da empresa hoteleira é o fato de que a qualidade do atendimento o diferencia, pois também vende este tipo de serviço (Embratur, 1998 apud Castelli, 1984).

Em muitos países os hotéis desempenham um importante papel tanto para a economia como para a divulgação da cultura própria daquela localidade, que acontece por meio da tipologia arquitetônica do edifício e do tipo de serviço prestado, como para fins de negócio, entretenimento, cultura, lazer ou até mesmo o público de suas proximidades que, geralmente, estão em busca de lazer (Medlik \& Ingram, 2002).

A hotelaria é um dos segmentos mais importantes do turismo, ela representa a espinha dorsal da indústria do turismo, sendo também uma significativa atividade empregadora (Martineli, 2001).

\section{O HOTEL E A HOSPITALIDADE}

A ideia de hospitalidade parece ser tão antiga quanto a própria civilização, pois o seu significado, em latim, é o ato de acolher, de bem receber, cujo radical deriva da palavra hospice (Walker, 2002). 
As raízes históricas da hospitalidade, para Grinover (2002), surgem no início do século XIII, na Europa. A palavra latina hospitalis designava a hospedagem gratuita e a atitude caridosa que era oferecida aos indigentes e viajantes, aqueles que eram acolhidos nos conventos, nos hospícios e nos hospitais. Também pode ter sido originada da palavra francesa hôtel, que significava casa do rei, termo que também foi utilizado para designar os edifícios suntuosos da aristocracia francesa, como o Hôtel dês Invalides, que desde 1670 abrigava os oficiais da pátria que estavam inválidos.

Grinover(2006) definehospitalidadecomo oacolhimentoa outrem, permitindo que adentre ao espaço. Este processo de interpretação e entendimento da inclusão de pessoas está diretamente relacionado a motivações pessoais, na relação que há entre o hóspede e o anfitrião, tendo o espaço forte influência nesta relação.

Já os estudos realizados por Camargo (2005) sobre hospitalidade dividemse em duas vertentes: a francesa, pautada nos princípios de "ir e vir" e do "darreceber-retribuir", além dos conceitos de hospitalidade pública e doméstica; e a americana, baseada nos fenômenos comerciais, no contrato firmado entre o hóspede e o anfitrião, muitas vezes realizado por agentes que intermediam as negociações.

A mensuração da hospitalidade, quando transpostas para o espaço construído, um hotel, passa pela compreensão das experiências de ver, sentir, ouvir, tocar e falar, vivenciadas pelos seus usuários, sensações que aguçam novos sentimentos, expectativas, vontades e valores, tornando-o sensível ao ambiente e aos elementos que o caracterizam como hospitaleiro.

Portanto, o edifício hoteleiro, além de ser uma obra especializada, cuja forma e a função têm como objetivo garantir a qualidade da operação hoteleira como produção arquitetônica e da paisagem, como implantação urbanística, também deve assegurar o bem-estar do hóspede e a rentabilidade do capital investido no empreendimento. Sendo assim, é pertinente afirmar que o valor comercial da hospedagem está associado ao valor emocional, ou seja, o processo de valoração pode estar associado à percepção do cliente sobre a experiência de hospedagem e opinião sobre a qualidade do ambiente (Spolon, 2009). 


\section{ITAJAÍ: DA GÊNESE ATÉ O XIX}

A crise do feudalismo europeu, no século XIV, impulsionou a ocupação das terras ultramarinas, levando à formação de impérios coloniais. Os primeiros a completar a unificação foram Portugal e Espanha, que com a intermediação do Papa Alexandre VII dividiu o mundo católico em dois segmentos, por meio do Tratado de Tordesilhas de 1494. Neste período, o Brasil era a mais extensa colônia portuguesa e, a partir das Organizações Régias, definiram-se as práticas de regularidade para o traçado e para as construções que compunham as novas vilas e cidades. A ocupação destas terras implicou o surgimento de novos hábitos de viver, de morar, novos costumes e adaptações dos mesmos à outra realidade geográfica, social e econômica (Mendes, Verissimo e Bittar, 2010).

Apesar do movimento de ocupação da costa brasileira já estar ocorrendo, foi no início do século XVII que as terras de Itajaí passaram a ser ocupadas. O Rio Itajaí-açu foi um atrativo para os portugueses, pois as características geográficas assemelhavam-se às procuradas nas demais colônias portuguesas. Mas foi no ano de 1658 que chega a estas terras o paulista João Dias D'Arzão, também fundador de São Francisco do Sul, para apropriar-se de uma sesmaria - lote colonial - às margens do Rio Itajaí, junto à Foz do Rio Itajaí-mirim, cujo objetivo era encontrar ouro, mas sua empreitada não obteve sucesso (D'ávila, 1982).

No ano de 1748, o Conselho Ultramarino autorizou o povoamento das costas catarinenses com imigrantes açorianos. A prática de recepção de imigrantes foi intensificada no litoral catarinense, em 1750, com a vinda de imigrantes da Ilha da Madeira e dos Açores, os quais desceram e direcionaram-se para a ocupação de toda a costa, de Laguna, passando por Desterro até São Francisco do Sul, incluindo o povoado de Itajaí. A coroa portuguesa recorreu a esta medida para resolver dois problemas, o excesso de população nos Açores e a necessidade de manter domínio sobre as terras no Cone-sul, mesmo sem objetivos econômicos. O resultado obtido até o ano de 1752 não atendeu às expectativas esperadas, pois as colônias deram pouco resultado, embora tenham assentado quatro mil imigrantes (Rothbarth, 2003). 
Quando os portugueses chegaram a Itajaí, encontraram índios da tribo Tupiguarani, fato que corroborou com o nome dado à cidade, o qual deriva de uma denominação indígena dada ao Rio Itajaí-açu (D'ávila, 1982).

Este território possuía uma ocupação esparsa, com pontos de concentração que se estendiam sempre do mar para o interior. A instalação de moradias ocorria em espaços com potencial para dar abrigo à navegação e que possibilitasse uma ligação com o interior. Este fato e a presença de madeira apropriada para a construção naval direcionaram as atividades dos primeiros moradores para a construção e o reparo de embarcações, levando ao desenvolvimento de uma mão de obra local especializada (D'ávila, 1982).

Em 1750 ocorre a posse de D. João, iniciando a Era Pombalina. Neste mesmo período, Portugal e Espanha assinam o Tratado do uti possidetis, reconhecendo os direitos de Portugal sobre os territórios a oeste do Tratado de Tordesilhas. E na década de 1763, a capital do Brasil é transferida de Salvador para o Rio de Janeiro, local que recebe a família real no ano de 1808 (Mendes, Verissimo \& Bittar, 2010).

A mais antiga referência quanto a números populacionais de Itajaí está em um requerimento datado de 1794, o qual afirma que havia mais de 40 moradores localizados nas margens do Itajaí. Documento este enviado ao vice-rei, alegando que as terras eram ocupadas e protestando contra a concessão das terras que estavam sendo intituladas de desertas e incultas (Rothbarth, 2003).

Mais tarde, em 1799, Joaquim Francisco de Salles e Mello, governador da Fortaleza de Santo Antônio de Ratones, solicita uma légua de terras para a instalação de uma fábrica de açúcar às margens do Rio Itajaí-açu. Em 1820, foi instalada a colônia de São Thomaz de Vilas Novas por Antônio Menezes de Vasconcelos Drumond, no atual bairro de Itaipava (Fundação Cultural de Itajai, 2009).

As primeiras referências ao porto datam de 1816, quando foram registradas por Paulo José Miguel de Brito em sua obra "Memória Política da Capitania de Santa Catarina", editada em Lisboa em 1829 (D’avila, 1982).

Em 1820, Antônio Menezes de Vasconcelos de Drumond foi aconselhado a mudar de ares, quando decidiu visitar a Capitania da Ilha de Santa Catarina, 
inteirando-se dos negócios do governo e soube das terras sem benfeitorias e apropriadas para o início da colonização. Assim, seguiu para Itajaí e deu início à colônia de São Tomás de Villanova. Em 1821, recebeu ordens para retornar ao Rio de Janeiro, pois o rei determinou o término de sua missão (D'ávila, 1982).

A partir de 1823 é que Itajaí passa a receber imigrantes, colonos não portugueses, principalmente alemães e italianos, os de outras etnias, como os africanos, os suíços e os sírio-libaneses, vieram em menor numero (D'ávila, 1982).

Foi no ano de 1824 que o comerciante Agostinho Alves Ramos, morador da província de Santa Catarina, adquiriu, de José Coelho da Rocha, um terreno situado junto à margem direita do rio no local de costumeiro reparo das embarcações, chamado de Estaleiro. Tornou-se um líder na comunidade, redigiu uma carta para o Bispo do Rio de Janeiro solicitando autorização para a criação do Curato e também participou da comissão que se encarregou da construção da primitiva capela do Santíssimo Sacramento com o cemitério anexo, atual Igreja Nossa Senhora das Graças. No ano de 1833, o curato do Santíssimo Sacramento do Itajaí passou à condição de Freguesia, desligando-se da Vila de São Francisco e passando a integrar o município de Porto Belo, semente que deu origem à cidade de Itajaí (D'ávila, 1982).

A Vila do Santíssimo Sacramento de Itajaí não passava de uma colônia de pescadores, local onde também se avultava o comércio da madeira, cada firma possuía o seu próprio veleiro para transporte da mercadoria para as praças do Rio de Janeiro e Santos. Mas foi em 12 de agosto de 1833 que o povoado foi elevado à Paróquia - Paróquia do Santíssimo Sacramento, cujo presidente da Província de Santa Catarina era Feliciano Nunes Pires (D'ávila, 1982).

Em março de 1834, com a morte de Frei Pedro Antônio Agote, o seu segundo vigário, Francisco José de Souza, assume a Paróquia de Itajaí. É importante ressaltar que a presença da igreja contribuiu com o fortalecimento da ocupação, pois esta desempenhava um importante papel socioeconômico e cultural cuja influência superava a de outras instituições, inclusive as governamentais (D'ávila, 1982).

Foi estabelecido, no ano de 1835, o primeiro plano de colonização do Vale do Itajaí, com a Lei Provincial $n^{\circ} 11$, de 5 de Maio, lei que estabelecia os direitos 
e os deveres dos colonos, bem como a divisão das terras em lotes. Agostinho Alves Ramos foi nomeado para organizar e supervisionar estes lotes, sendo sucedido por João Dias da Silva Mafra, deputado da Assembleia Provincial. A Lei Provincial $n^{\circ}$ 9, de 15 de abril de 1835, cria a primeira escola pública de Itajaí (Rothbarth, 2003).

Em 1840, D. Pedro dá o golpe da maior idade, assume o trono e a economia do Brasil muda, fazendo com que se torne o maior produtor mundial de café (Mendes, Verissimo e Bittar, 2010).

Em 1843, em todo o perímetro urbano, contavam-se umas cinquenta casas, entrando nesse número pequenos ranchos miseráveis, cobertos de palha, de um só compartimento, com paredes feitas apenas de ripas fincadas juntas umas das outras. Todas as casas tinham as paredes externas de taipa, isto é, pau-a-pique amarrado com ripa e barreadas, apenas três ou quatro delas eram caiadas. A única casa diferente era a do Major Agostinho, que era construída de pedra, tijolos e cal (Rothbarth, 2003).

Na década de 1850, na região próxima à foz do Rio Itajaí, a configuração das ruas assemelhava-se com as demais povoações brasileiras. Eram marcadas pela linearidade e pela irregularidade geradas pelas ruas tortas, esquinas em ângulos diferentes e com variação da largura dos logradouros. As vias eram margeadas por casarios próximos, que geralmente se dispunham em direção a um ponto de interesse comum. As ruas mais importantes eram a Lauro Muller (antiga Rua d'Eu) e Pedro Ferreira, as únicas que possuíam residências, 14 na primeira e 10 na segunda (D'avila, 1982).

O desenvolvimento da cidade ocorreu apenas após o início da Colônia de Blumenau, em 1850, quando as casas de comércio, agentes de navegação extra provincial e bancos estrangeiros estabeleceram-se na cidade em virtude do Porto de Itajaí. Estes estabelecimentos chegaram a controlar toda a distribuiç̧ão dos produtos importados e se encarregavam do transporte das mercadorias locais. Eles eram os representantes dos produtos europeus, fato que beneficiou a importação de produtos para a indústria. Como agentes bancários, ajudaram a suprir o deficiente sistema financeiro global (Rothbarth, 2003). 
A partir do final da década de 1850 se iniciam as mudanças políticas e administrativas na cidade. Em 1859, a Paróquia do Santíssimo Sacramento foi elevada à categoria de Vila e, no ano seguinte, 1860, o município de Itajaí foi oficialmente fundado. Fato que acelerou o desenvolvimento das atividades portuárias, uma vez que não estaria mais subordinada à Câmara Municipal de Porto Belo (D'avila, 1982).

Em 1865 foi construída a primeira estrada ligando a Colônia Blumenau à Barra do Rio Itajaí, seguindo o mesmo traçado da atual Rodovia Jorge Lacerda. A Lei $n^{\circ} 603$, de 13 de abril de 1868, cria a comarca de Itajaí, sendo seu primeiro juiz o Dr. Joaquim da Silva Ramalho. É nessa ocasião que se constitui a Câmara Municipal e ocorre a implantação do Pelourinho - símbolo de aplicação da justiça e do poder local (D'avila, 1982).

Uma das principais atribuições da Câmara era a elaboração do Código de Postura que funcionava como uma espécie de Lei Orgânica Municipal. No Artigo 120 do Código de Postura, estava estabelecido que os proprietários eram obrigados a calçar suas testadas com oito palmos de largura, seguindo o nivelamento da rua e que os contraventores seriam multados. Neste período, mesmo com o Código de Postura, a população tentava burlar a lei (D'avila, 1982).

As casas comerciais de maior porte pertenciam às famílias Malburg, que eram negociantes de madeira do setor de importação e exportação, da representação de companhias de navegação e de bancos. Já a família Konder enriqueceu mais tarde com a exportação de madeira e tornaram-se agentes do Banco Nacional do Comércio e do Banco Alemão Transatlântico (Rothbarth, 2003)

O século XX inicia. Em 1902 foi construído o Farol de Cabeçudas, que baliza a entrada da barra do Rio Itajaí-açu e, em 1906, as obras do Porto de Itajaí já atingiam a margem direita do rio, onde hoje se localiza a Avenida República Argentina. Nesta área foram construídos os primeiros trapiches. A iluminação elétrica foi inaugurada em 1910, cujo concessionário era Max Puetter, a firma que pertencia a Félix Busso Assebürg (Rothbarth, 2003; D'ávila, 1982).

Atualmente, o núcleo urbano inicial, atual centro histórico, demarcado pelo plano diretor municipal, é o local de permanência de parte do traçado urbano do século XVIII e também área de concentração dos edifícios monumentais do século XIX. 


\section{O HOTEL EM ITAJAÍ NO SÉCULO XIX}

O desenvolvimento das atividades portuárias de importação e exportação alavancou também o desenvolvimento dos equipamentos de hospedagem de Itajaí.

Nesta época, segundo Mamede (2002), no Brasil do século XIX não havia registros de normatização ou classificação para o setor hoteleiro, a primeira lei de incentivos surgiu em 1904, no Rio de Janeiro, e em 1978 foi criada a primeira classificação de hotéis oficial para o Brasil.

Como nesta época não havia entidade regulamentadora que armazenasse documentos sobre os edifícios que eram construídos na cidade, as incursões exploratórias de campo foram realizadas junto aos acervos de documentos históricos na seção de registros sobre a evolução urbano-arquitetônica, econômica e social na Fundação Genésio Miranda Lins, Fundação Cultural de Itajaí e Palácio Marcos Konder - Museu Histórico de Itajaí. Vale ressaltar que estes dados coletados em campo foram comparados com as informações obtidas por meio de pesquisa bibliográfica com intuito de demonstrar sua veracidade.

Sendo assim, o mais antigo registro sobre hotel, Figura 1, foi encontrado no acervo da Fundação Genésio Miranda Lins (2001), o qual data do dia 25 de Fevereiro de 1886, publicação do Jornal A Idéa, intitulado Periódico Neutro de Itajahy, o qual enaltece o sistema de hospitalidade do Hotel do Commercio, "Recebe pensionistas e oferece boa hospedagem aos viajantes (Boa meza e comodidade nos preços)" de autoria de Gabriel Heil. Não foram encontrados mais registros de nenhuma natureza sobre este edifício nem seu endereço.

A ênfase do texto de jornal está em demonstrar, por meio de palavras, que os hóspedes que utilizam os serviços do Hotel do Commércio são bem acolhidos. A manchete enaltece o ato do bom recebimento, o qual se relaciona ao conceito de hospitalidade, logo às motivações pessoais, descrito por Grinover (2006). O recorte de jornal aborda as motivações que geram o bem receber, a boa hospedagem e a boa comida, tudo isto a preços cômodos. 
Figura 1: Publicação do Jornal a Idéa de1886 sobre o Hotel do Commercio.

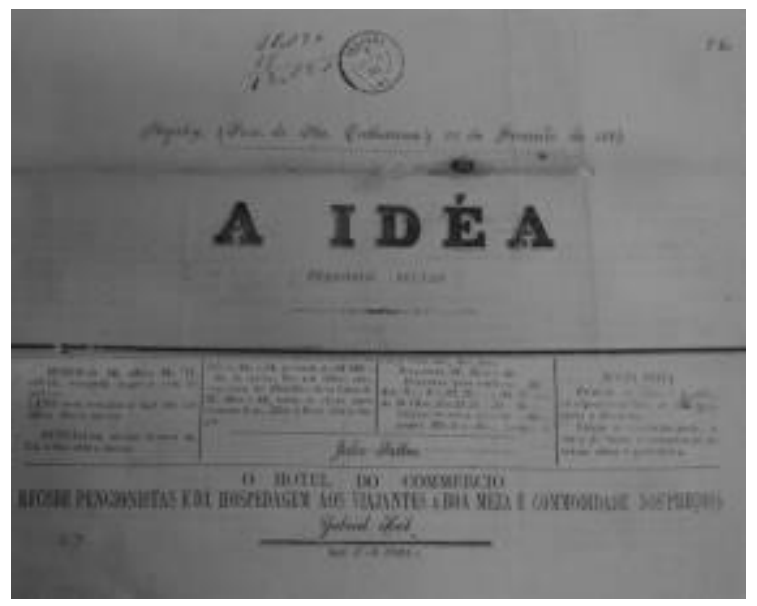

Fonte: Fundação Genésio Miranda Lins (2001).

Outro importante edifício é o Hotel Brazil, Figura 2, cujos registros estão na Fundação Cultural de Itajaí (2001) e informam que até hoje este equipamento permanece junto à atual Rua Lauro Muller, inicialmente chamada de Rua Conde d'Eu e depois de Rua da Praia. Este empreendimento passou por vários proprietários e também mudou de nome, atualmente é intitulado de Hotel Rota do Mar. As imagens a seguir demonstram as fachadas, a primeira, logo após a sua construção, momento áureo do edifício para a sociedade local. E a segunda evidencia a fachada atual que foi tombada por meio de lei municipal. Apesar das funções de hospedar, bem receber, ponto de encontro da sociedade, o local perdeu todo o glamour que possuiu no passado. A fachada do atual Hotel Rota do Mar compõe um dos mais importantes conjuntos arquitetônicos do século XIX do centro histórico de Itajaí.

Este hotel foi inaugurado em 1897, quando era administrado por Alexius Reiser e pela Companhia Malburg. Nesta época, além do serviço de hospedagem, sua sede era utilizada para reuniões de negócios. Já durante o século XX, durante a primeira Guerra Mundial, foi o ponto de informações para a comunidade, local onde a população buscava saber sobre os acontecimentos que massacravam o continente europeu. Ali também eram armazenadas as correspondências trazidas pelos emissários que faziam o elo entre Itajaí e o além mar. Esse cenário se repetiu na Segunda Guerra Mundial (Galatto, 2012).

Este hotel foi um referencial da grandeza, pois lá se encontravam pessoas ilustres e homens de negócios. Os executivos que ali se alojavam também 
discutiam a vida da cidade. Também sediava os eventos mais requintados da sociedade, como a Academia de Cortar Vestidos para Senhoras (Galatto, 2012).

Figura 2: Fotografia do Hotel do Brazil, sec. XIX

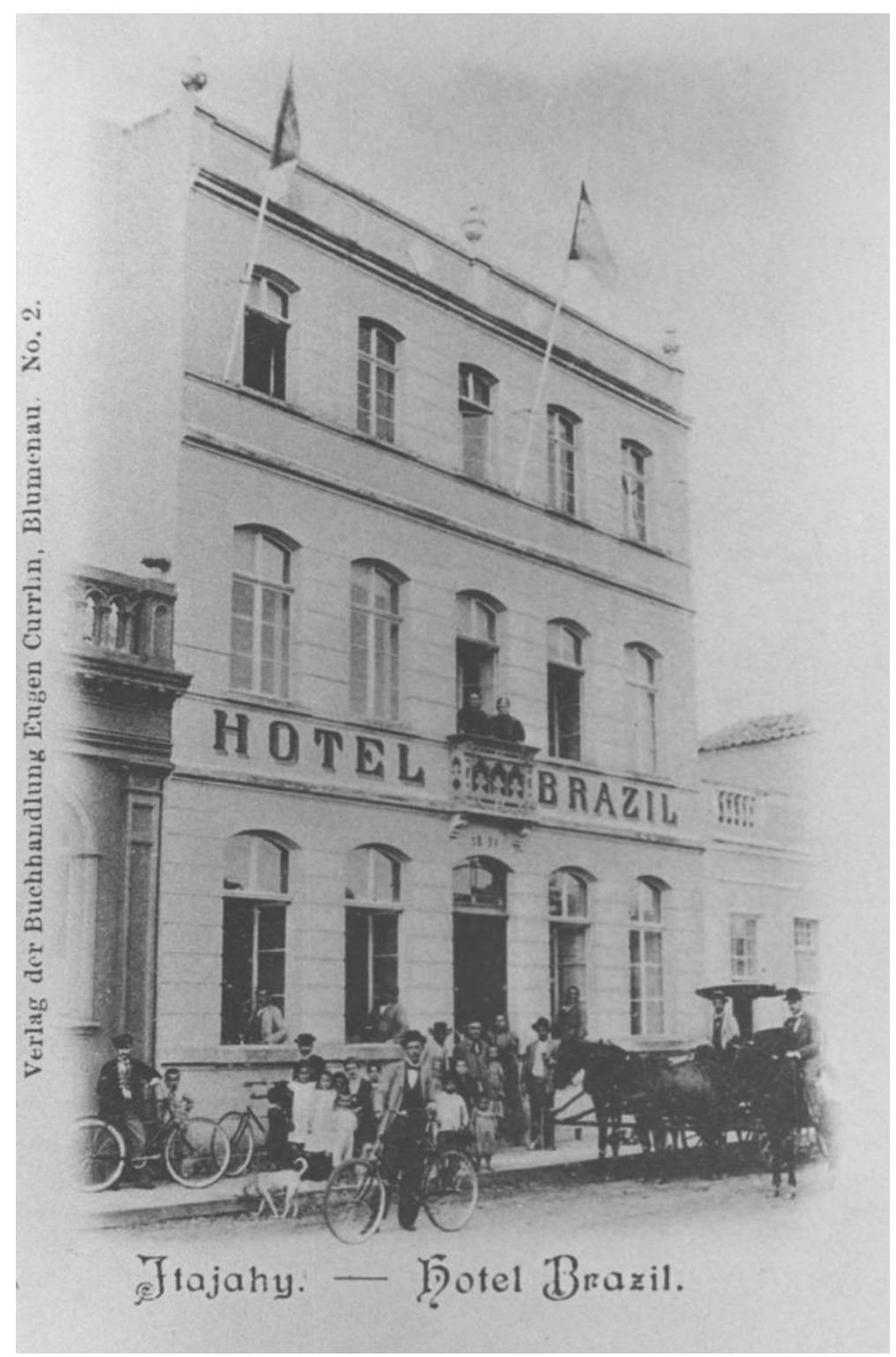

Fonte: Fundação Genésio Miranda Lins, 2001.

É um edifício que foi construído com espessas paredes, possuía eiras e beiras, grandes aberturas e um pé direito que proporcionava conforto térmico ao local, e sacadas de ferro forjado. Sua arquitetura foi inspirada nos estilos romântico e neoclássico, a qual caracterizava a burguesia brasileira do final do século XIX. Também foi chamado de sobrado república, pois demonstrava o poder da elite (Fundação Cultural de Itajaí, 2001).

O acervo histórico da Prefeitura Municipal de Itajaí (1994) possui algumas plantas do edífico original inaugurado no ano de 1897, como a fachada principal, Figura 3 e as plantas do térreo, primeiro e segundo pavimentos, Figura 4. 
Figura 3: Fachada e detalhamento das aberturas

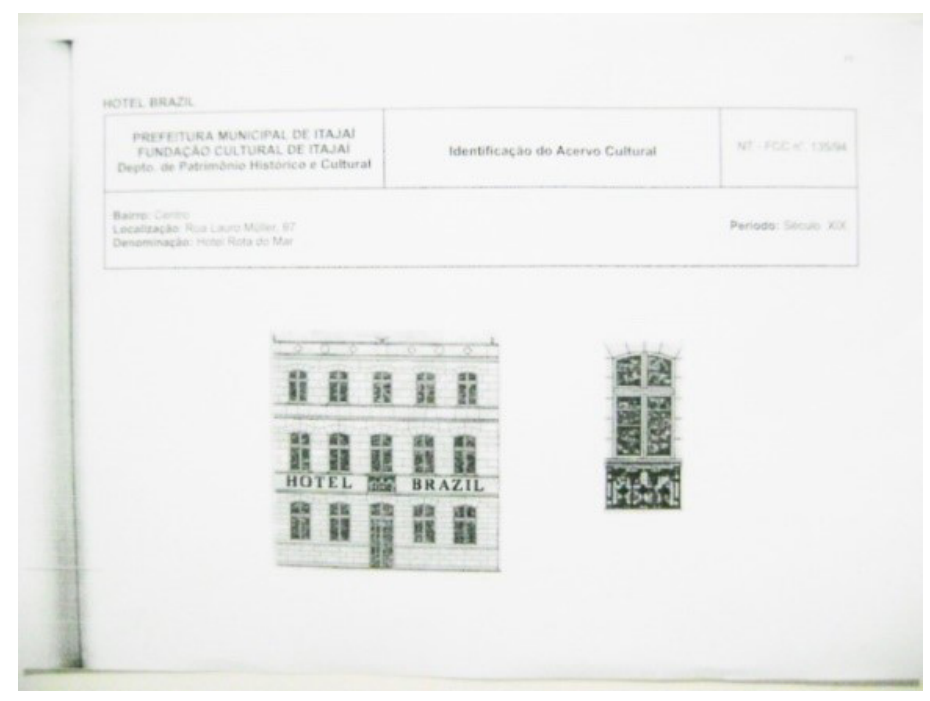

Fonte: Prefeitura Municipal de Itajaí, 1994.

Figura 4: Plantas Baixas

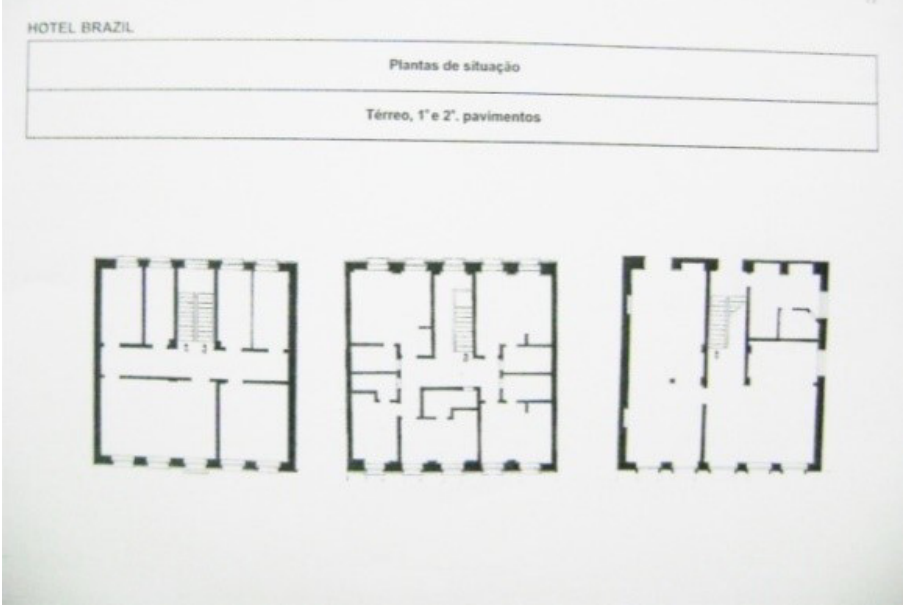

Fonte: Prefeitura Municipal de Itajaí, 1994.

Esta tipologia arquitetônica do século XIX, segundo Reis Filho (1987), era uma continuação dos padrões coloniais, utilizavam as mesmas técnicas construtivas e os layouts internos obedeciam à lógica setecentista, havia uma superficial vinculação ao neoclássico e posterior ecletismo europeu. A mão de obra usada para construção era escrava e não havia sistema de água e esgoto. Já a atuação dos arquitetos estrangeiros e seus discípulos no Brasil contribuíram para a modificação formal da arquitetura, assim como o aperfeiçoamento das técnicas construtivas. O térreo das edificações assumiu um uso refinado, deixou de ser destinado ao abrigo de lojas, depósito e acomodações para os escravos e passou a ser construído sobre porões altos. Os cômodos, como os salões junto à fachada principal, abrem-se para a rua e para a face interna do terreno onde 
ficavam os quartos, salas de jantar e ao fundo a área de serviços. Os edifícios possuíam portas altas, com bandeiras para melhorar o arejamento, influência das posturas higiênico-sanitárias, medidas que tinham como objetivo reduzir os miasmas, pois a sociedade vivia muitas epidemias e pestes devido à presença de ambientes com pouca ventilação, iluminação e salubridade (Gunn, 1998), modelos instituídos pelos mestres portugueses.

Os grandes salões, que se abriam para a rua, eram locais que recebiam a comunidade, um empreendimento acolhedor não apenas para seus hóspedes, mas também para a sociedade, permitindo que atividades de utilidade pública e política fossem ali desenvolvidas, demonstrando o quão hospitaleiro era este empreendimento.

Vale ressaltar que a arquitetura neoclássica no Brasil era impregnada de racionalismo, economia e austeridade estética, apesar da influência do romantismo europeu, fato que impulsionou o estabelecimento da estética eclética (Mendes, Verissimo \& Bittar, 2010).

Na Figura 5, estão registrados dados sobre a tipologia arquitetônica original e algumas transformações que foram realizadas ao longo do tempo, assim como sobre o sistema construtivo. Apesar de não possuir especificações dos ambientes no desenho, deduz-se que a sequência seja da direita para a esquerda, térreo com dois grandes salões na fachada junto à via. No primeiro pavimento, cinco unidades habitacionais com banheiro. Crê-se que os banheiros sejam uma adição, pois não era comum no século XIX ter instalações sanitárias individuais. Nesta época, a influência do movimento sanitarista ainda era recente, mas os ambientes destinados ao repouso não possuíam janelas, as alcovas, as quais mais tarde foram proibidas. Para os dormitórios, a presença de aberturas para a face externa do edifício passou a ser obrigatória, assim como ter banheiros, seguindo as orientações das posturas higiênico-sanitárias (Chalhoub, 1996).

E no segundo pavimento dois grandes cômodos, salões, junto à fachada principal e quatro pequenos nos fundos, talvez tenham abrigado grandes suítes e dormitórios, respectivamente. Como atualmente o edifício não apresenta mais este layout e o proprietário atual desconhece os usos anteriores, não foi possível identificar os reais usos. 
Figura 5: Registros tipológicos, históricos e sistema construtivo do Hotel do Brasil.

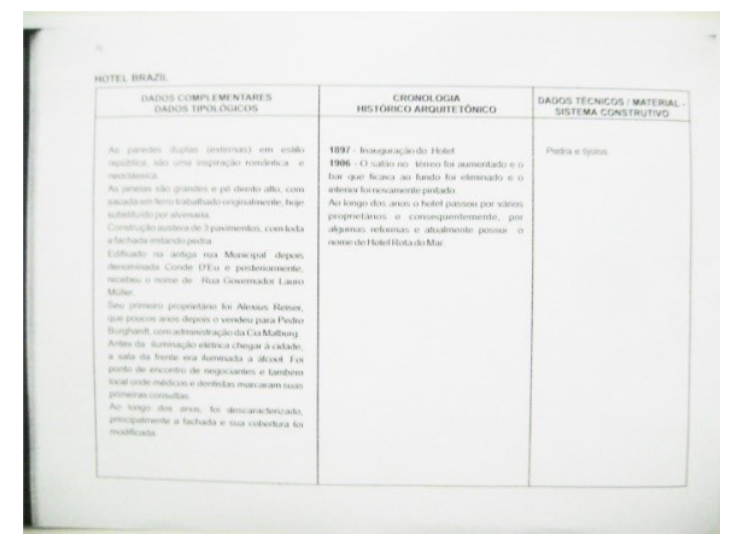

Fonte: Prefeitura Municipal de Itajaí, 1994.

Na Fundação Genésio Miranda Lins (2001) há, no arquivo, um jornal sobre o Hotel Central, Figura 6, de propriedade de Otto D. Moldenhauer, cuja manchete chama para os "excelentes" aposentos e todas as comodidades, como bons banheiros e um jardim para recreio. Não foram encontrados registros sobre a tipologia arquitetônica deste hotel.

Os recortes de jornal sobre o Hotel do Commercio e o Hotel Central apresentam chamadas para os hóspedes baseadas em princípios de hospitalidade, de bem receber, como uma maneira de atrair a clientela, demonstrando o quanto os viajantes eram exigentes com relação a suas escolhas de hospedagem. Certamente influenciados não somente pelas transações financeira que ocorriam nesta cidade, mas também pelos movimentos em prol da prevenção das grandes epidemias que estavam sendo vividas, principalmente nas grandes urbes, decorrentes de crescimentos desenfreados destas metrópoles, que transformaram as cidades em grandes "cloacas".

Figura 6: Propaganda sobre os serviços oferecidos pelo Hotel do Hotel do Central

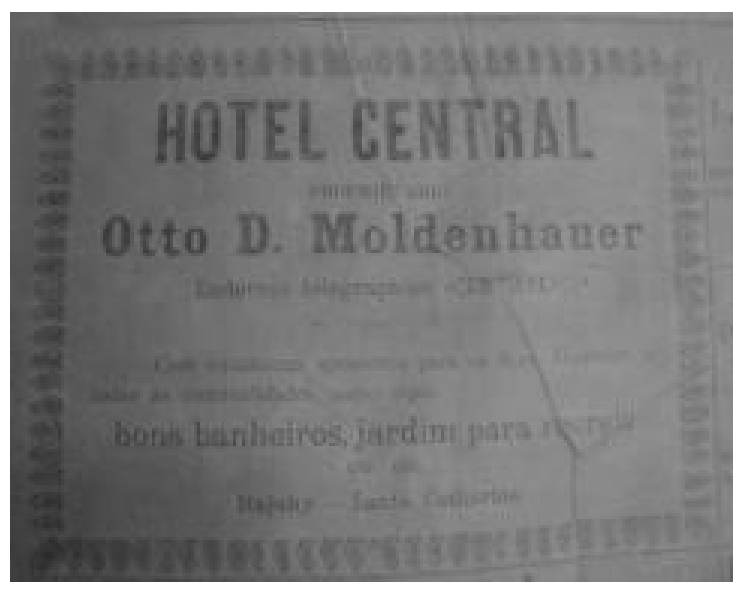

Fonte: Fundação Genésio Miranda Lins, 2001. 
Na manchete da Figura 7, também há uma chamada para o Hotel Brasil, cuja nomenclatura já havia mudado, escrito com a letra "s" em vez de " $z$ ", e o nome da rua também mudou, passando a ser chamada de Rua Lauro Muller, quando o edifício passara a ser de propriedade de Alex Reiser. Também consta neste mesmo recorte de jornal um artigo sobre o Hotel Helvetia, de propriedade de Jacob Heusi, localizado na Rua Hercílio Luz, esquina com Rua Victória (Fundação Genésio Miranda Lins, 2001).

Outra manchete de jornal, Figura 8, versa sobre o Hotel D. Pedro, localizado na Rua Hercílio Luz esquina com a Rua Victoria, que era de propriedade da viúva Bertha Scheefer e estava sob a gerência de Paulo Scheeffer. Este hotel oferecia aos viajantes cômodas hospedagens, dispunha de todos os cômodos necessários para este tipo de estabelecimento. "Limpeza, comodidade e aceio": frase que era o mote deste empreendimento. Enfatizando não somente a presença de conforto para o hóspede, mas também as questões sanitárias, limpeza e asseio, tão em voga neste período em que as posturas sanitárias estavam sendo implantadas.

Figura 7: Publicação em jornal: serviços oferecidos pelo Hotel Helvetia e Brasil

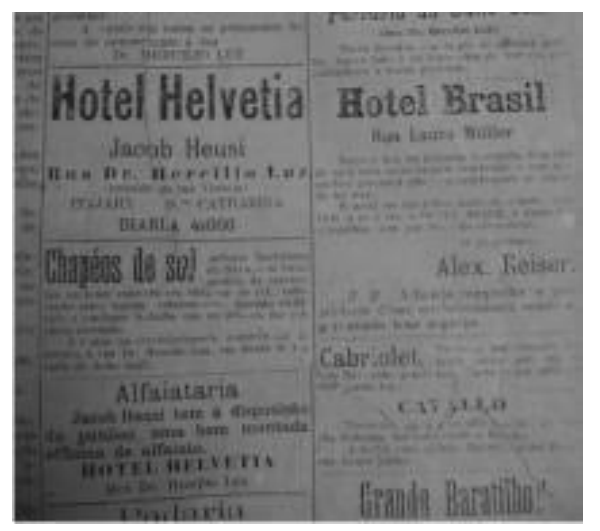

Fonte: Fundação Genésio Miranda Lins, 2001.

Figura 8: Propaganda publicada em jornal sobre os serviços oferecidos pelo Hotel D. Pedro

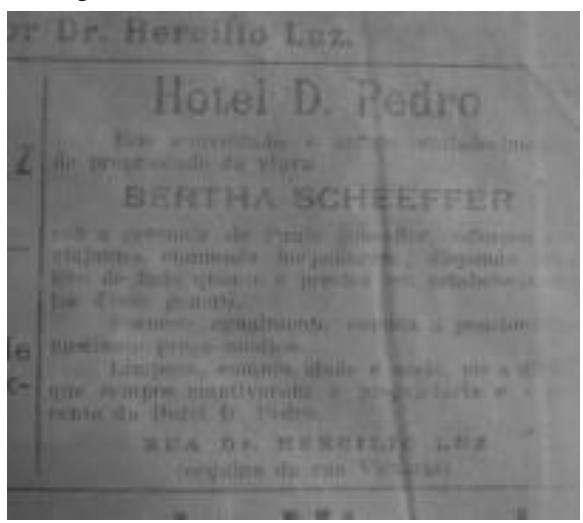

Fonte: Fundação Genésio Miranda Lins, 2001. 
Na Figura 9 consta a localização de alguns dos hotéis, que segundo os registros, prestavam serviços à sociedade itajaiense no século XIX. Observou-se que estes edifícios estavam junto às áreas próximas ao porto, principal elemento propulsor da economia desta cidade e também as principais vias do núcleo urbano desta época, atual centro histórico. Vale ressaltar que os demais hotéis citados neste artigo deixaram de constar nesta figura pelo fato de inexistirem seus endereços.

Figura 9: Mapa com a localização dos hotéis cujos registros estão em artigos de jornais do século XIX

Fonte: Prefeitura Municipal de Itajaí, com intervenções do autor.

Pode-se verificar que muitos foram os hotéis que serviam a cidade nesta época, no entanto poucas análises de edifício, propriamente dito, puderam ser realizadas, pois plantas e imagens só foram encontradas do Hotel Brazil, atual Hotel Rota do Mar. No entanto, por meio das manchetes de jornal, além de ter sido possível identificar a existência de outros edifícios, também possibilitou constatar o quanto eram utilizadas palavras que se reportam à hospitalidade, como ambientes arejados, limpos, boas camas, comodidade, acesso a jardim (espaços abertos, arejados), dentre outras.

Outro fato relevante foram os dados que se referem à salubridade dos ambientes. Acredita-se que as recentes ondas de pestes e epidemias vividas pela sociedade da época e as descobertas das formas que estas doenças eram 
transmitidas estimulavam a imprensa a divulgar informações sobre a salubridade dos ambientes como sinônimo de qualidade.

\section{CONSIDERAÇÕES FINAIS}

Esta averiguação possibilitou identificar quais foram os hotéis que serviram a cidade de Itajaí do século XIX; bem como o quanto as posturas higienistas influenciaram as manchetes que divulgavam os meios de hospedagem. Desse modo, pôde-se interpretar que tais posturas higienistas puderam contribuir para a melhoria da qualidade das unidades habitacionais e também das demais áreas de uso coletivo dos hotéis; o conforto, o bem-estar e o bom uso também descrevem um espaço "agradável" fruído no hotel.

Os espaços de uso coletivo destes hotéis, muitas vezes, ampararam eventos para os próprios cidadãos itajaienses (festas, casamentos, bailes, formaturas, etc.), denotando-se, então, como áreas que preservam uma memória social, muitas vezes coletiva, fazendo com que estes espaços dos hotéis se tornem uma referência de lugar, essencialmente, como um lugar festivo da e na cidade.

Se o hotel configura como um lugar urbano, pode-se concluir que a ele é atribuído o título de marco urbano; se ele é um marco urbano, é dotado de hospitalidade.

Marcos desta natureza deveriam permanecer, pois relatam a história desta sociedade vivida em diversos momentos da história, mas esta não é a realidade desta cidade, pois se constatou a inexistência de registros físicos de quase todos os edifícios hoteleiros, fato que parece estar se tornando o retrato da realidade brasileira.

Retrato este que está sendo construído a duras penas, com a perda da memória e da identidade cultural, elementos essenciais para a formação de uma sociedade futura. Acredita-se que isto se deva, também, à forte influência exercida pelos incorporadores imobiliários, que desejam expandir o seu patrimônio particular, junto aos gestores públicos, responsáveis pela elaboração de políticas públicas urbanas preservacionistas. 
Sendo assim, chavões como o patrimônio edificado "anoitece", mas não "amanhece" estão norteando as transformações morfológicas das cidades.

Outra situação que corrobora com esta problemática é a falta de divulgação para a população dos novos instrumentos urbanísticos, tal como o Estatuto da Cidade, que prevê mecanismos para um desenvolvimento equilibrado e sustentável das cidades, como troca do direito de construção e operações urbanas específicas para núcleos culturais.

Atualmente, são poucos os grupos que compreendem a importância da manutenção destes bens culturais, pois os movimentos em prol da educação e da sensibilização patrimonial são novos, datam do século passado. A sociedade organizada brasileira, em geral, começou a se preocupar com as questões patrimoniais somente no século XX, momento em que o "mito" de que o Brasil ainda é um país jovem começa a se esvair, e as pessoas passam a se atentar para os problemas que vêm se agravando com o decorrer do tempo.

Problemas similares aos encontrados em Itajaí, cidade que vem perdendo a herança que deveria deixar para as gerações futuras, seus bens duráveis, os edifícios, que testemunharam as ambições e as aspirações, individuais ou coletivas daquele grupo. Assim como os processos de mutação que ocorreram ao longo do tempo e que demonstram o desenvolvimento e/ou as crises, tenham sido elas tecnológicas, culturais, econômicas ou políticas.

Constatou-se a permanência de poucos registros sobre as características físicas dos outros hotéis identificados, no entanto existe a possibilidade de estes hotéis não terem sido cadastrados em algum órgão, em virtude das dificuldades operacionais relacionadas à construção civil da época e também, se cadastrados, da dificuldade em armazenar e conservar anotações em papel.

Esta realidade faz com que investigações desta natureza fiquem quase sem respostas, em virtude da permanência de poucos registros, prejudicando a produção científica, instrumento que nutri a sociedade de novos saberes. 
No entanto, apesar das limitações, foi possível identificar que alguns dos conceitos de hospitalidade estudados foram materializados por meio do objeto arquitetônico, ou seja, observado em um projeto arquitetônico hoteleiro, o qual apresenta questões relacionadas à fidelização do cliente.

Recomenda-se que esta experiência seja replicada para outras tipologias arquitetônicas e para outras localidades, pois somente com a realização de investigações se estará contribuindo com a identificação de peculiaridades, sejam elas provenientes da hospitalidade ou de outros conceitos que possam estar presentes em elementos patrimoniais que relatam a história da sociedade local, com suas singularidades culturais, episódio que lhes confere autenticidade e as transformam em um produto cobiçado por investidores de diversas áreas, particularmente, do turismo.

\section{REFERÊNCIAS BIBLIOGRÁFICAS}

Andrade, N., Brito, P. L., \& Jorge, W. E. (1998) Introdução a Turismo e Hotelaria. São Paulo: Senac Nacional.

Atrativos Turisticos. (s.d.). Fundação Itajaiense de Turismo. Disponível em: http.://www. fitur. itajai.sc.gov.br. Acesso em 20 de Maio de 2011.

Beni, M. C. (2003) Análise Estrutural do Turismo. São Paulo: Senac.

Camargo, L. O. (2005) A pesquisa em hospitalidade. Hospitalidade, Pp.15-51.

Campos, L. C. (1998) Introdução a turismo e hotelaria. Rio de Janeiro: Senac Nacional.

Castelli, G. (1982) Turismo e Marketing: uma abordagem hoteleira. Porto Alegre: Sulina.

Chalhoub, S. (1996) Cidade febril - cortiços e epidemias na Corte Imperial. São Paulo: Companhia das Letras.

D’avila, E. (1982) Pequena História de Itajaí. Itajaí: Prefeitura Municipal de Itajaí.

Duarte, V. V. (1996) Administração de Sistemas Hoteleiros: conceitos básicos. São Paulo: Senac.

Galatto, B. (2012) Mural Histórico de Itajaí. Disponível em: http://muralhistoricodeitajai. blogspot.com.br/search/label/-\%20HOTEL\%20 BRASIL. Acesso em: 02 de 05 de 2015. 
Grinover, L. (2002) A Hospitalidade urbana: acessibilidade, legibilidade e identidade. Revista Hospitalidade. 29 - 50.

Gunn, P. (s. d.) Projetos e intervenções urbanisticas intervenções urbanísticas e sanitarismo. Entre os miasmas e o contágio: os embates entre a medicina e a doença na gestão da cidade no Brasil. Campinas: São Paulo.

Histórico dos Bens Tombados do município de Itajaí, 2009. Disponível em: Fundação Genesio Miranda Lins. Acesso em: 02 de Maio de 2015.

Lima, R. M. (2013) A construção social-histórica do turismo como prática moderna. Turismo: Estudos \& Práticas.

Mamede, G. (2002) Manual de direito para a Administração hoteleira: incluindo análise dos problemas e dúvidas jurídicas, situações estranhas e as soluções previstas no direito. São Paulo: Atlas.

Martineli, J. C. (2001) Fundamentos multidisciplinares do turismo: hotelaria. In: M. G. Ansarah, Turismo: como aprender, como ensinar. São Paulo: Senac.

Medklin, S. e (2002) Introdução à Hotelaria: gerenciamento e serviço. Rio de Janeiro: Campus.

Mendes, C., Verissimo, C. e Bittar, W. (2010) Arquitetura no Brasil de Dom João VI a Deodoro. Novo Milênio.

Ouriques, H. R. (2005) A Produção do Turismo: fetichismo e dependência. Campinas: Alínea.

Patrimônios Arquitetônicos de Itajaí (2009) Fundação Cultural de Itajaí. Disponível em: http: // www. fitur.itajai.sc.gov.br. Acesso em: 20 de Maio de 2009.

Pires, M. J. (2001) Raízes do Turismo no Brasil. São Paulo: Manole.

Raffestin, C. (1993) Por Uma Geografia do Poder. Atica.

Rothbarth, M. (2003) Famílias de Itajaí: mais de um século de história. Itajaí: Prefeitura Municipal de Itajaí.

Spolon, A. P. (2009) Sob os domínios da Hospitalidade: revisão teórica e proposições. VI Seminário da Associação Brasileira de Pesquisa e Pós- Graduação em Turismo. São Paulo: Universidade Anhembi Morumbi.

Urry, J. (1996) O olhar do turista: lazer e viagens nas sociedades contemporâneas. São Paulo: Nobel. 
Trigo, L. G. (2000) A sociedade pós-industrial e o profissional em turismo. Campinas: Papirus.

Walker, J. R.(2002) Introdução à hospitalidade. São Paulo: Manole.

\section{CONTRIBUIÇÃO DOS AUTORES NA CONSTRUÇÃO DO ARTIGO}

ROSSINI: Elaboração da proposta, coordenação do projeto e redação do texto final para a revista.

TOMELIN: Pesquisa bibliográfica sobre hotelaria.

SOLANO: Participou como bolsita da pesquisa bibliográfica e de campo. 